\title{
Daniel Moulinet, Genèse de la laïcité. À travers les textes fondamentaux de 1801 à 1959
}

Paris, Le Cerf, 2005, 289 p.

Muriel Pic

\section{OpenEdition}

\section{Journals}

Édition électronique

URL : http://journals.openedition.org/assr/4001

DOI : 10.4000/assr.4001

ISSN : $1777-5825$

Éditeur

Éditions de l'EHESS

Édition imprimée

Date de publication : 1 décembre 2006

Pagination : 115-283

ISBN : 2-7132-2124-2

ISSN : 0335-5985

\section{Référence électronique}

Muriel Pic, « Daniel Moulinet, Genèse de la laïcité. À travers les textes fondamentaux de 1801 à 1959 »,

Archives de sciences sociales des religions [En ligne], 136 | octobre - décembre 2006, document 136-78, mis en ligne le 13 février 2007, consulté le 21 septembre 2020. URL : http://journals.openedition.org/ assr/4001; DOI : https://doi.org/10.4000/assr.4001

Ce document a été généré automatiquement le 21 septembre 2020

(C) Archives de sciences sociales des religions 


\title{
Daniel Moulinet, Genèse de la laïcité. À travers les textes fondamentaux de 1801 à 1959
}

Paris, Le Cerf, 2005, 289 p.

\author{
Muriel Pic
}

Professeur à l'Université catholique de Lyon et prêtre du diocèse de Moulins, Daniel Moulinet trace une "genèse de la laïcité » à travers les textes institutionnels qui ont conduit et prolongé la loi de séparation de l'Église et de l'État en 1905. L'ouvrage qui se réfère d'emblée aux travaux de Jean-Marie Mayeur, Catholicisme social et démocratie chrétienne (1986) ne se présente pas comme une synthèse historique ou une thèse politique. Son but est d'opérer un retour aux textes législatifs et aux textes du magistère ecclésial afin d'offrir au lecteur une somme lui permettant d'étayer ses propres analyses. Au fil de la chronologie des régimes politiques, de 1801 à 1959, les relations entre les deux institutions sont données à lire à travers leurs textes, article après article, l'auteur supprimant ceux qui, à son avis, sont de moindre importance pour le thème, tout en reconnaissant qu'il y a là, forcément, « une part d'arbitraire ». Excellent outil de travail pour le chercheur s'intéressant aux relations entre religion et modernité, cet ouvrage dégage les trois principaux aspects de ces textes de loi: l'enseignement, le culte, et l'aménagement géographique et économique des diocèses. Chacune des sections des sept chapitres est ouverte par un bref commentaire résumant avec efficacité les enjeux essentiels des lois présentées et est accompagnée d'une bibliographie. Une brève introduction indique que la publication de l'ouvrage commémore le centenaire de la séparation de l'Église et de l'État en 1905. Il prend soin de rappeler que cette notion de laïcité dont le terme n'a pas d'équivalent à l'étranger on parle de " tolérance religieuse »- est en germe dans les articles 10 et 11 des Droits de l'Homme sur la liberté des opinions et leur communication.

2 Le point de départ de l'ouvrage est le Concordat de 1801 passé entre Pie VII et Bonaparte où l'organisation concordataire relève strictement de l'État. Au lendemain de ce que l'on peut raisonnablement désigner comme l'événement traumatique du 
catholicisme, la Révolution française, ce dernier n'est plus la "religion d'état». Les exemples les plus concrets de cette transformation est la mainmise sur l'enseignement public par l'État qui met en place les lycées et donne tout pouvoir, pour le supérieur, à "l'Université impériale» composée de cinq ordres de Facultés: théologie, droit, médecine, sciences mathématiques et physiques, lettres. Mais encore, au niveau du culte : l'obligation du mariage civil, la reconfiguration géographique des cimetières devant être transférés hors des périmètres habités. Enfin, il y a la création des fabriques qui ont pour charge de gérer l'économie et la vie intérieure des paroisses. Les cultes protestants sont placés sous le contrôle du gouvernement, et il en sera de même des personnes de confession juive, sauf que l'on trouve à leur endroit un décret dit « infâme » qui «annul[e] la plupart de leurs créances et règlement[e] les métiers qu'[elles] peuvent exercer ». Les décrets de 1808 sur le culte israélite seront développés en 1844 dans la perspective centralisatrice du droit concordataire. Si, de la Restauration à la fin du Second empire en 1870 (date à laquelle disparaissent les États pontificaux, formellement abolis en 1929 par les Accords de Latran), l'instabilité politique n'est pas propice à une montée radicale de la laïcité, la Troisième République va se caractériser par un durcissement du processus. Après la restauration religieuse tentée par le régime d'ordre moral établit dans une France vaincue par la Prusse, l'année 1875 marque, en effet, une nouvelle étape pour une laïcité républicaine. C'est "l'avènement d'une nouvelle société [qui] va se traduire par un certain nombre de lois visant à la laïcisation des institutions et un renfermement de la religion dans la sphère privée ». Le ralliement de l'Église catholique à la République sous l'impulsion de Léon XIII tente d'«éviter que les Catholiques, assimilés à l'option monarchiste, ne s'isolent définitivement de la vie politique ». Ceux-ci sont alors divisés entre ceux qui se rallient et ceux qui refusent (encyclique Inter sollicitudines de 1892). Mais l'anticléricalisme ne s'apaise pas: les congrégations sont les premières attaquées (notons que les jésuites, ordre à vocation éducative, ont été déjà nommément expulsés lors des décrets d'obligation d'autorisation pour les congrégations en 1880), et l'on aboutira finalement à la loi de 1901 sur les associations.

3 Le point d'arrivée de l'ouvrage est la loi Debré sur le rapport entre l'État et les établissements d'enseignement privé. Plus que le contrôle du spirituel par l'État, la laïcité pose en effet la question scolaire, celle-ci demeurant tout au long de l'évolution des lois un enjeu de taille en raison du poids originel des congrégations dans ce domaine. Ainsi, le passage du monopole religieux sur l'éducation à l'école gratuite et obligatoire est ponctué par divers moments, notamment la loi Falloux qui réglemente l'enseignement primaire et secondaire et établit l'obligation d'ouvrir une école de filles dans les communes de plus de 800 habitants. À cette période, en 1850, le rôle octroyé à l'Église est celui de défenseur de la morale, et c'est sous la surveillance du curé que l'instituteur est tenu à l'enseignement du catéchisme. Mais en réalité, ce droit de regard n'est déjà plus qu'un reste du pouvoir religieux sur l'éducation dont il fut le tenancier. Sur cette question, en 1904, la loi de suppression de l'enseignement congréganiste fondera les conflits (rupture diplomatique) entre le Saint-Siège et l'État, atmosphère dans laquelle est donnée la loi de séparation. Si la liberté du culte est garantie, les ministres des cultes sont interdits d'acte politique. Néanmoins, le rapport de l'institution religieuse au politique ne peut être neutralisé comme le montrent les condamnations du Sillon par Pie X en 1910 et de l'Action Française par Pie XI en 1926. Mais surtout, ce qui marque la loi de séparation, c'est la création d'associations cultuelles refusées par Pie X (encyclique Vehementer nos) ce qui entraînera un 
aménagement du mode d'application de la loi. Sous cet angle, il apparaît clairement que la loi de 1901 sur les associations a été mise en place pour trouver une solution aux congrégations religieuses. Pie XI (1924, encyclique Maximam gravissimamque) accepte alors une nouvelle formule, les associations diocésaines, et c'est après la Grande Guerre qu'elles seront mises en place grâce à la Chambre "bleu horizon» qui, composée d'anciens combattants, témoigne que l'expérience de la guerre a rapproché l'Église catholique et la nation. Avec la Seconde Guerre mondiale, Vichy, gouvernement favorable aux cléricaux, assouplit la loi de séparation, mais le STO et la concrétisation de l'antisémitisme avec les premières rafles de 1942 conduisent les catholiques à protester (Lettre sur la personne humaine de Mgr Saliège). L'Assemblée constituante de 1946, majoritairement rouge à ses débuts, puis réélue, met en place l'Assemblée nationale et le Conseil de la république. Elle « réaffirme l'engagement de l'État dans l'organisation de l'enseignement public et laïque ». La constitution de 1958 dont est chargée De Gaulle - rappelé à la tête de l'État en raison de la situation en Algérie -, " donne la première place au président de la république, chargé de l'exécutif, et met en place deux chambres : l'Assemblée nationale et le Sénat. (...) L'article premier réaffirme le principe de laïcité ». La séparation de l'Église catholique et de l'État français est donc consommée.

4 L'ouvrage de Daniel Moulinet permet ainsi de mesurer la distance qui sépare la réalité, l'histoire et les lois, en donnant accès à des textes fastidieux à se procurer et dont on ne connaît la plupart du temps pas les nuances. À ce titre, et comme le propose l'auteur, le présent ouvrage est, plutôt qu'une thèse ou une histoire de la laïcité, un instrument de travail pour entrer dans des débats actuels, face à la question du culte islamique, prioritairement. Ce qui apparait encore bien dans cet ouvrage, au fil des textes qu'il nous donne à lire, c'est le double mouvement propre à la sécularisation, de repli des institutions religieuses, sous le coup des lois laïques, mais aussi de déplacement des croyances à d'autres espaces sociaux, en premier lieu le culturel. La loi protégeant les édifices religieux (1905) et l'inventaire des biens de l'art sacré (1906) montre cette conversion progressive des instruments du rituel. Du cultuel au culturel, se dessine donc cette notion de sécularisation éminemment problématique face à celle de laïcisation (Hans Blumenberg, Die Legitimität der Neuzeit, 1966, trad. 1999) dans la mesure où l'on ne sait si l'on doit les distinguer ou les confondre. Autre réflexion en laquelle l'ouvrage de Moulinet peut s'avérer être un outil précieux. 